\title{
Adsorptive Behavior of an Activated Carbon for Bisphenol A Removal in Single and Binary (Bisphenol A-Heavy Metal) Solutions
}

\author{
M.A. Martín-Lara ${ }^{1, * \mathbb{C}}$, M. Calero ${ }^{1, *}$, A. Ronda ${ }^{2}$, I. Iáñez-Rodríguez ${ }^{1}$ and C. Escudero ${ }^{3}$ \\ 1 Departamento de Ingeniería Química, Universidad de Granada, Avda, Fuentenueva, s/n, 18071 Granada, \\ Spain; ireneir@ugr.es \\ 2 Departamento de Ingeniería Química y Ambiental, Universidad de Sevilla, Camino de los descubrimientos, \\ s/n, 41092 Sevilla, Spain; aronda@us.es \\ 3 Departamento de Tecnología de Alimentos, Instituto Nacional de Investigación y Tecnología Agraria y \\ Alimentaria (INIA), Ctra. de A Coruña, km 7.5, 28040 Madrid, Spain; carlos.escudero@inia.es \\ * Correspondence: marianml@ugr.es (M.A.M.-L.); mcaleroh@ugr.es (M.C.); Tel.: +34-958-240-445 (M.A.M.-L.); \\ +34-958-243-315 (M.C.)
}

Received: 29 June 2020; Accepted: 28 July 2020; Published: 30 July 2020

\begin{abstract}
Bisphenol A (BPA) is an extensively produced and consumed chemical in the world. Due to its widespread use, contamination by this pollutant has increased in recent years, reaching a critical environmental point. This work investigates the feasibility of bisphenol A adsorption from industrial wastewater solutions, testing the reduction of bisphenol A in synthetic solutions by a commercial activated carbon, AC-40, in batch mode. Besides, mixtures of bisphenol A and different heavy metal cations were also studied. So far, no works have reported a complete study about bisphenol A removal by this activated carbon including the use of this material to remove BPA in the presence of metal cations. First, adsorption experiments were performed in batch changing $\mathrm{pH}$, dose of adsorbent, initial bisphenol A concentration and contact time. Results showed greater retention of bisphenol A by increasing the acidity of the medium. Further, the percentage of bisphenol A adsorbed increased with increasing contact time. The selected conditions for the rest of the experiments were $\mathrm{pH} 5$ and a contact time of $48 \mathrm{~h}$. In addition, an increase in retention of bisphenol A when the dose of adsorbent increased was observed. Then, specific experiments were carried out to define the kinetics and the adsorption isotherm. Equilibrium data were adequately fitted to a Langmuir isotherm and the kinetics data fitted well to the pseudo-second-order model. The maximum adsorption capacity provided by Langmuir model was $94.34 \mathrm{mg} / \mathrm{g}$. Finally, the effect of the presence of other heavy metals in water solution on the adsorption of bisphenol A was analyzed. Binary tests revealed competition between the adsorbates and a significant selectivity toward bisphenol A. Finally, the study of the adsorption performance in three consecutive adsorption-desorption cycles showed efficiencies higher than $90 \%$ in all cycles, indicating that the activated carbon has good reusability.
\end{abstract}

Keywords: activated carbon; adsorption; bisphenol A; equilibrium; heavy metals

\section{Introduction}

Bisphenol A (BPA) is recognized as a dangerous endocrine disruptor. It causes a number of hazardous effects on living beings such as fertility damage and fetal development problems [1-3]. It has been extensively used as a crude material in the industrial production of epoxy resins and polycarbonate plastics, which accounted for nearly $64 \%$ of BPA demand in 2018. These polycarbonate resins are mainly consumed in the electronics, construction and automotive industries. In terms of country distribution, high demand is concentrated in emerging consumers such as China, India, 
Southeast Asia and Brazil. China is the largest player in the BPA industry, accounting for half of BPA's global consumption. Western Europe and the United States are the other important players in the BPA market [4].

As a consequence, concentrations of BPA are present both in surface waters as well as industrial wastewaters [5-7]. For all those reasons, novelty alternatives have been proposed for its removal from wastewater during recent years [8]. BPA is present in various types of water at different concentrations. For instance, it has a concentration of $17.2 \mathrm{mg} / \mathrm{L}$ in hazardous waste landfill leachate $[9,10], 12 \mu \mathrm{g} / \mathrm{L}$ in stream water [11], between 3.5 and $59.8 \mathrm{ng} / \mathrm{L}$ in drinking water [7] and around $100 \mathrm{mg} / \mathrm{L}$ in effluents from polycarbonate factories [6,12].

Due to its high industrial yield and toxicological effect, the elimination of BPA from water solutions is of great importance and it has been listed as a priority pollutant in water treatment [13]. Several separation techniques such as adsorption, advanced oxidation, membrane separation, phytoremediation and photocatalysis, among others, have been applied to efficiently remove BPA from water effluents $[14,15]$. Particularly, among wastewater treatment technologies, phytoremediation is arousing attention because it is a promising ecologically friendly alternative to remove BPA from contaminated soil and water systems. For example, Phouthavong-Murphy et al. [9] investigated the potential of two United States native switchgrass varieties for BPA removal and found good BPA removals over approximately three months. Further, advanced oxidation processes are interesting due to their good performance in the degradation of BPA and other micropollutants. Recently, Luo et al. [16] studied the rapid removal of BPA and other organic micropollutants by heterogeneous peroxymonosulfate catalysis and reported that BPA had the highest removal efficiency at $\mathrm{pH} 9.0$, almost $100 \%$ removal. Other researchers [17] integrated advanced oxidation processes with membrane filtration to form a catalytic membrane that demonstrated exceptional efficiency for instantaneous degradation of BPA. Moreover, the development of cheap and eco-friendly, effective and rapid remediation technologies for the removal of BPA has increased the investigations based on the use of transition metal-based nanomaterials for photocatalysis. For example, Rani et al. [18] synthesized and examined green zinc and cobalt ferrites nanoparticles for the degradation of BPA from water under direct sunlight. Results showed very good efficiencies, similar to those found with $\mathrm{ZnO}, \mathrm{Co}_{3} \mathrm{O}_{4}$ and $\mathrm{Fe}_{2} \mathrm{O}_{3}$ nanoparticles.

Even novel technologies are being investigated with very good results: one of the most favorable methods is traditional adsorption onto carbonaceous materials [19]. Particularly, activated carbons have good characteristics to work as an adsorbent: high porosity and surface area (around $3000 \mathrm{~m}^{2} / \mathrm{g}$ ), high degree of surface reactivity and diverse characteristics of surface chemistry $[20,21]$. Due to these characteristics, activated carbons have been used for many different applications: as adsorbents, catalysts or catalyst supports. They have been tested as a cleaning material for removing pollutants from gaseous or liquid phases and the purification or recovery of chemicals [22,23]. Adsorption on activated carbon is one of the first water treatments to have been used $[24,25]$ and it is recognized by the United States Environmental Protection Agency (US EPA) as one of the best methods for removing organic and inorganic compounds from water for human consumption. The aqueous-phase adsorption of both organic and inorganic compounds has been a very important application of activated carbons. In fact, around $80 \%$ of the world production of activated carbons is used in liquid-phase applications [26,27].

The adsorption mechanism of activated carbons is due to interactions (electrostatic or non-electrostatic) between the carbon surface and the adsorbate. The nature of these interactions, which can be attractive or repulsive, depends on the: (a) charge density of the carbon surface, (b) chemical characteristics of the adsorbate and (c) ionic strength of the solution. Non-electrostatic interactions are always attractive and can include: (a) van der Waals forces, (b) hydrophobic interactions and (c) hydrogen bonding.

Activated carbons can be manufactured by physical or chemical activation processes using a wide range of raw materials. Physical activation uses high temperature for the carbonization of the original 
material in absence of oxygen (usually $\mathrm{CO}_{2}$ or steam atmosphere). During chemical activation, the material is impregnated with a chemical agent prior to its carbonization. One of the most frequent chemical agents extensively used for the production of activated carbons in industry is $\mathrm{H}_{3} \mathrm{PO}_{4}[28,29]$.

Adsorptive removal of BPA from wastewater solutions by carbon-based materials, such as activated carbon, has been extensively studied [30-35]. For example, Juhola et al. [31] prepared a biomass-based adsorbent with a BPA adsorption capacity of $41.5 \mathrm{mg} / \mathrm{g}$. Pan et al. [33] investigated the BPA adsorption on carbon nanomaterials that showed a very good potential for the removal of BPA of waters. Redding et al. [34] studied the adsorption of BPA on various modified lignite carbons. Specifically, the work demonstrated that these modified carbons prepared using high-temperature steam or methane/steam offered better behavior than conventional activated carbons. However, there are few works available focusing on the BPA removal from water when other types of contaminants are also present in the water [36-39]. BPA is a high-volume industrial chemical used in the production of epoxy resins and polycarbonate plastics. Further, different additives are added in these materials to improve the performance of the plastics. The chemical substances used as additives can be very different depending on the objective. The additives can include metal-containing additives such as heavy metals as cadmium, copper, lead or zinc, among others [40]. Heavy metals are another important type of pollutants that have been found in waters. Some researchers have analyzed the simultaneous adsorption/biosorption of these priority pollutants (heavy metals and organic pollutants) [41-43]. The influence of heavy metals could enhance the removal of BPA or perhaps they could compete with BPA for the available active sites and decrease the removal of BPA when the removal of BPA and heavy metals is carried simultaneously.

Hence, one of the objectives of this investigation is to study the interactions between some of the most common heavy metals in wastewater environments and BPA during adsorption onto activated carbon (AC-40 commercial sample). First, the single adsorption of BPA on AC-40 activated carbon was investigated. The main factors influencing the adsorption process were analyzed. Then, the simultaneous adsorption of BPA and heavy metal cations on AC-40 activated carbon was performed in order to know the type of adsorption (competitive or cooperative) which occurs between BPA and these metal cations. Finally, desorption of BPA in three consecutive cycles was analyzed. Although the study has been performed using a commercial activated carbon, so no novel findings about the material are given, there are not a wide range of research works in the literature about the use of AC- 40 for the removal of BPA from wastewaters including (1) the effect of the main parameters, (2) a kinetics study, (3) an isotherms study, (4) simultaneous adsorption of BPA and heavy metals and (5) desorption. The authors consider that specific complete studies about the removal of emergent pollutants with the current technology (adsorption on activated carbons) can be interesting since they increase the knowledge in this field and can be applied in the industrial wastewater sector.

\section{Materials and Methods}

\subsection{Adsorbent}

Activated carbon trademark CECA S.L., known as AC-40, was used as an adsorbent in all the experiments. It is an extruded, thermally activated carbon from bituminous coal with a high surface area $\left(1200 \mathrm{~m}^{2} / \mathrm{g}\right)$. The main features of this adsorbent have been determined by Méndez Díaz et al. [44], Abdel Daiem et al. [45] and Velo-Gala et al. [46]. Table 1 shows a summary of the properties. 
Table 1. Main physic-chemical characteristics of activated carbon AC-40.

\begin{tabular}{cc}
\hline Median particle diameter $(\mathrm{MPD})(\mathrm{mm})$ & 3 \\
Density $(\mathrm{g} / \mathrm{L})$ & 450 \\
Moisture content $(\%)$ & 4 \\
Specific surface area $\left(\mathrm{m}^{2} / \mathrm{g}\right)$ & 1201 \\
Pore volumes (mean widths of micropores $0.71 \mathrm{~nm})\left(\mathrm{cm}^{3} / \mathrm{g}\right)$ & 0.406 \\
Pore volumes (diameter between 6.6 and $50 \mathrm{~nm})\left(\mathrm{cm}^{3} / \mathrm{g}\right)$ & 0.046 \\
Pore volumes (diameter $>50 \mathrm{~nm})\left(\mathrm{cm}^{3} / \mathrm{g}\right)$ & 0.409 \\
Concentration of acidic groups $(\mu \mathrm{eq} / \mathrm{g})$ & 907.7 \\
Concentration of basic groups $(\mu \mathrm{eq} / \mathrm{g})$ & 96.0 \\
Point of zero charge $\left(\mathrm{pH} \mathrm{pzc}_{\mathrm{pzc}}\right)$ & 7.5 \\
$\% \mathrm{C}$ & 68.97 \\
$\% \mathrm{H}$ & 1.03 \\
$\% \mathrm{~N}$ & 0.45 \\
$\% \mathrm{~S}$ & 1.02 \\
$\% \mathrm{O}$ & 20.23 \\
$\% \mathrm{Ash}$ & 8.30 \\
\hline
\end{tabular}

\subsection{Reagents}

BPA, $\mathrm{C}_{15} \mathrm{H}_{16} \mathrm{O}_{12}$, with $100 \%$ purity of Sigma-Aldrich company was used. Solutions of BPA were prepared by dissolving BPA in ultrapure water obtained from Milli-Q ${ }^{\circledR}$ equipment (Millipore). In adsorption tests conducted with mixtures of $\mathrm{BPA}$ and metal cations, copper (II) nitrate, $\mathrm{Cu}\left(\mathrm{NO}_{3}\right)_{2} \cdot 3 \mathrm{H}_{2} \mathrm{O}$, lead (II) nitrate, $\mathrm{Pb}\left(\mathrm{NO}_{3}\right)_{2}$, nickel (II) nitrate, $\mathrm{Ni}\left(\mathrm{NO}_{3}\right)_{2} \cdot 6 \mathrm{H}_{2} \mathrm{O}$, and cadmium (II) nitrate, $\mathrm{Cd}\left(\mathrm{NO}_{3}\right)_{2} \cdot 4 \mathrm{H}_{2} \mathrm{O}$, were used. All of them had purity higher than $98 \%$ and they were supplied by Panreac Quimica S.A. company.

\subsection{Methodology}

All adsorption experiments were conducted in batch mode in a stirred tank. BPA solutions were prepared in ultrapure water using a mild ultrasonic bath with a temperature of approximately $50{ }^{\circ} \mathrm{C}$ (323 K).

In the preparation of mixtures of BPA and metal cations, the proper amount of metal reagent was added to the previously prepared solution of BPA.

Each solution was located in a jacketed reactor with a capacity of $250 \mathrm{~mL}$ and maintained at a constant temperature $(298 \mathrm{~K})$ with stirring throughout the test by using a magnetic stirrer. When the operation time finished, a liquid sample was taken from the reactor by using an automated pipette. Moreover, a sample of the original solution was taken. The concentrations of initial and final contaminants were determined. Consequently, it was possible to determine the percentage of contaminant removed by the activated carbon.

The effect of main experimental conditions such as adsorbent dose, $\mathrm{pH}$, contact time and initial BPA concentration was studied changing the variables between the following ranges: adsorbent dose $(0.1-1.0 \mathrm{~g} / \mathrm{L}), \mathrm{pH}(3-10)$, contact time $(0.5-48 \mathrm{~h})$ and initial BPA concentration (1-160 mg/L) at a constant temperature of $25^{\circ} \mathrm{C}$. The desired value of $\mathrm{pH}$ was obtained by adding $\mathrm{HCl}$ solution $(0.1 \mathrm{M})$ or $\mathrm{NaOH}$ solution $(0.1 \mathrm{M})$ to the BPA solution. The real initial concentrations of BPA obtained in a $\mathrm{pH}$ range of 3-10 were measured in absence of the adsorbent.

To test the effect of $\mathrm{pH}$ on the adsorption process of BPA with activated carbon AC-40, an initial concentration of BPA of $20 \mathrm{mg} / \mathrm{L}$, a contact time of $48 \mathrm{~h}$ and an adsorbent concentration of $0.5 \mathrm{~g} / \mathrm{L}$ were selected. The $\mathrm{pH}$ of the medium was changed from 3 to 10 . The temperature remained constant at 25 ${ }^{\circ} \mathrm{C}$. Then, experiments were performed at $\mathrm{pH}$ values between 4 and 8 at different contact times in order to analyze the influence of contact time on the BPA removal efficiency.

To determine the minimum amount of activated carbon necessary to achieve maximum removal of BPA, experiments were carried out with a BPA initial concentration of $20 \mathrm{mg} / \mathrm{L}$, three contact times 
5.5, 22 and $48 \mathrm{~h}$ and a pH of 5, changing the concentration of the adsorbent from 0.1 to $1 \mathrm{~g} / \mathrm{L}$. The temperature remained constant during the tests at $25^{\circ} \mathrm{C}(298 \mathrm{~K})$.

The initial concentration of BPA is one of the most influential parameters in determining the contaminant removal on activated carbon from the aqueous solution. Experiments were carried out to test the effect of the BPA concentration in the adsorption process. A pH value of 5 with an adsorbent concentration of $0.5 \mathrm{~g} / \mathrm{L}$, and a contact time of $48 \mathrm{~h}$ were selected. The initial concentration of BPA was changed from 1 to $160 \mathrm{mg} / \mathrm{L}$.

To analyze the kinetics of BPA adsorption, experiments were performed with different contact times (until a contact time of $48 \mathrm{~h}$ ), at $\mathrm{pH}=5$ and a BPA initial concentration of $20 \mathrm{mg} / \mathrm{L}$, with an adsorbent dose of $0.5 \mathrm{~g} / \mathrm{L}$ and at a temperature of $298 \mathrm{~K}$.

BPA adsorption isotherms of the activated carbon AC- 40 were carried out at $\mathrm{pH} 5$ and a temperature of $298 \mathrm{~K}$. For this purpose, $100 \mathrm{~mL}$ of solutions containing different concentrations (1-160 mg/L) of BPA and $0.05 \mathrm{~g}$ of activated carbon were introduced into jacketed reactors, which were capped with flexible polyethylene (LDPE) film to avoid evaporation, prevent contamination and protect the solid-liquid system inside the reactor. Adsorption equilibrium was established when the concentration of BPA did not change (for 3 days). The BPA removal efficiency and the amount of BPA adsorbed by gram of activated carbon were calculated by the Equations (1) and (2), respectively:

$$
\begin{gathered}
\% \text { Removal efficiency }=\frac{\left(C_{i}-C_{f}\right)}{C_{i}} \times 100 \\
q=\frac{\left(C_{i}-C_{f}\right)}{m} \times V
\end{gathered}
$$

where $C_{i}$ and $C_{f}$ are the initial and final concentrations of BPA in solution, respectively, $\mathrm{mg} / \mathrm{L}, \mathrm{q}$ is the amount of BPA adsorbed by gram of adsorbent, $\mathrm{mg} / \mathrm{g}, \mathrm{m}$ is the mass of adsorbent, $\mathrm{g}$, and $\mathrm{V}$ is the volume of the solution, $\mathrm{L}$.

The procedure to obtain the data of adsorption of BPA on the activated carbon in the presence of metal cations was similar to methods to obtain adsorption results of single BPA systems. The only difference was the addition of a specific content of some metal cations to each BPA solution. Tests were performed with a concentration of $20 \mathrm{mg} / \mathrm{L}$ for both BPA and each metal cation, with an activated carbon dose of $0.5 \mathrm{~g} / \mathrm{L}$, during a contact time of $48 \mathrm{~h}$ and at $\mathrm{pH}$ value of 5 . When equilibrium was reached, the BPA and different metal cations concentrations were analyzed.

The determination of the content of BPA was performed by ultraviolet-visible (UV-Vis) spectrophotometry, using the spectrophotometer model Genesys 6. The BPA concentration was determined by absorbance measurements at $277.5 \mathrm{~nm}$. All the samples were collected in triplicate to further ensure precision. Samples used filled three quarters of the $1 \mathrm{~cm}$ cell used in the UV-Vis spectrophotometer. This amounted to approximately $1.5 \mathrm{~mL}$ of sample. In binary tests, the determination of metal content was performed by atomic absorption spectrophotometry, using the spectrophotometer model Perkin-Elmer AAnalyst 200.

Desorption of the BPA adsorbed onto the AC-40 was studied in a batch system. First, adsorption was performed at pH 5 and an initial BPA concentration of $20 \mathrm{mg} / \mathrm{L}$ with a dose of AC-40 of $0.5 \mathrm{~g} / \mathrm{L}$. Then, desorption was performed under the following desorption conditions: use of a mixture of methanol/acetic acid of $4: 1(\mathrm{v} / \mathrm{v})$, a dose of AC- 40 of $0.5 \mathrm{~g} / \mathrm{L}$, operation time of $48 \mathrm{~h}$ and temperature of $25^{\circ} \mathrm{C}$, and when the operation time was finished, the supernatant was separated and analyzed by ultraviolet-visible spectrophotometry at $277.5 \mathrm{~nm}$.

\section{Results and Discussions}

\subsection{Influence of $\mathrm{pH}$ and Contact Time}

The $\mathrm{pH}$ is one of the main parameters that control the removal of compounds present in aqueous solutions using solid adsorbents. According to several authors, $\mathrm{pH}$ can change the availability and 
characteristics of the pollutants in solution and it can modify the chemical state of the functional groups that are responsible for adsorption [47-49].

Some experiments were performed to test the effect of $\mathrm{pH}$ on the adsorption process of BPA with activated carbon AC-40. Figure 1 shows the results.

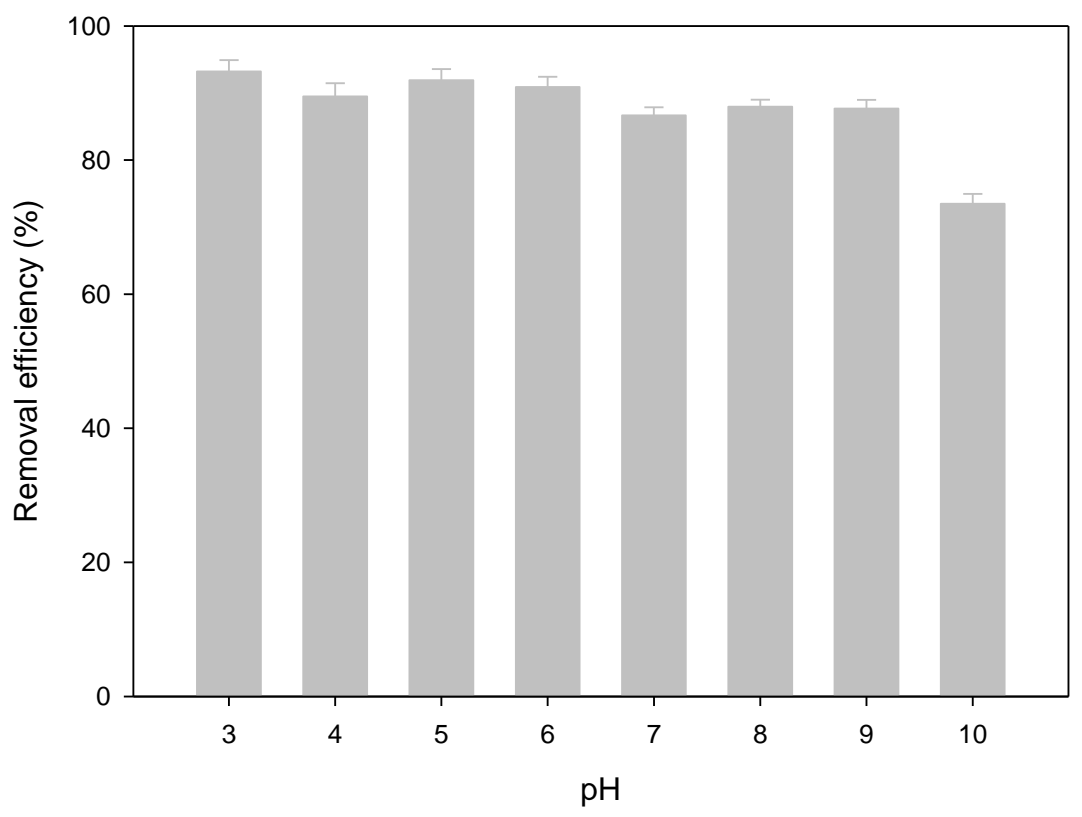

Figure 1. Bisphenol A (BPA) removal efficiency of activated carbon AC-40 according to the $\mathrm{pH}$ of the medium.

Data showed that $\mathrm{pH}$ did not significantly affect BPA adsorption. However, a slight tendency to obtain greater retention by increasing the acidity of the medium was observed. It could be because the zero point of charge was 7.5. The zero point of charge is the $\mathrm{pH}$ at which the surface of the adsorbent is globally neutral. Besides, it is a fundamental parameter of a material surface, governing the adsorbent-adsorbate interactions. Below this point, the surface is positively charged, otherwise it is negatively charged. Therefore, the CA surface was predominantly positive at $\mathrm{pH}$ values lower than 7.5. In contrast, negative charges appeared on the surface at $\mathrm{pH}$ values higher than 7.5 due to the dissociation of functional groups. In addition, BPA showed different states of equilibrium in an aqueous solution depending on the $\mathrm{pH}$. BPA could be found in its molecular form at a $\mathrm{pH}$ less than 8. Deprotonation of the bisphenolate monoanion occurred at a $\mathrm{pH}$ of 8 [49], reaching a considerable concentration at $\mathrm{pH} 9$ [50]. Therefore, electrostatic interactions between the negative charge of the surface of the activated carbon and bisphenolate anion could lead to a decrease in the overall adsorption of BPA. However, other interactions could also influence the adsorption rather than electrostatic forces, making the effect of surface charge less intense.

These results were in good agreement with those reported by other researchers. Thus, Wang and Xiao [51] indicated that the adsorption of BPA with four different activated carbons decreased at values of $\mathrm{pH}$ higher than 9. Chang et al. [52] found that the $\mathrm{pH}$ had an important role in the retention process of BPA with an activated carbon prepared from rice straw. Soni and Padmaja [53] also studied the adsorption of BPA on activated carbon prepared from palm shell. They found that at $\mathrm{pH}$ values below 9, the adsorption of BPA was not influenced by the $\mathrm{pH}$ of the medium. Bohdziewicz and Liszczyk [54] found a decrease in the adsorption of BPA by commercial activated carbon at $\mathrm{pH}$ values higher than or equal to 10. However, at $\mathrm{pH}$ values below 10, the adsorption capacity was not affected.

Figure 2 shows the BPA removal efficiency of activated carbon with different contact times. The removal efficiency increased with increasing contact time. At $\mathrm{pH} 5$, the amount adsorbed increased quickly in the first $0.5 \mathrm{~h}$ of contact. Then, at $22 \mathrm{~h}$, an adsorption percentage of $80 \%$ was reached. If 
the process continued until $48 \mathrm{~h}$, the adsorbed percentage would increase approximately up to $91 \%$. Finally, at $72 \mathrm{~h}$ of operating time, the removal of BPA reached a value of $92 \%$ (a very low change with respect to $48 \mathrm{~h}$ ). At other $\mathrm{pH}$ values, as $\mathrm{pH} 7$ or $\mathrm{pH} 8$, the adsorption was performed in a more progressive way. However, the change between 48 and $72 \mathrm{~h}$ was also low.

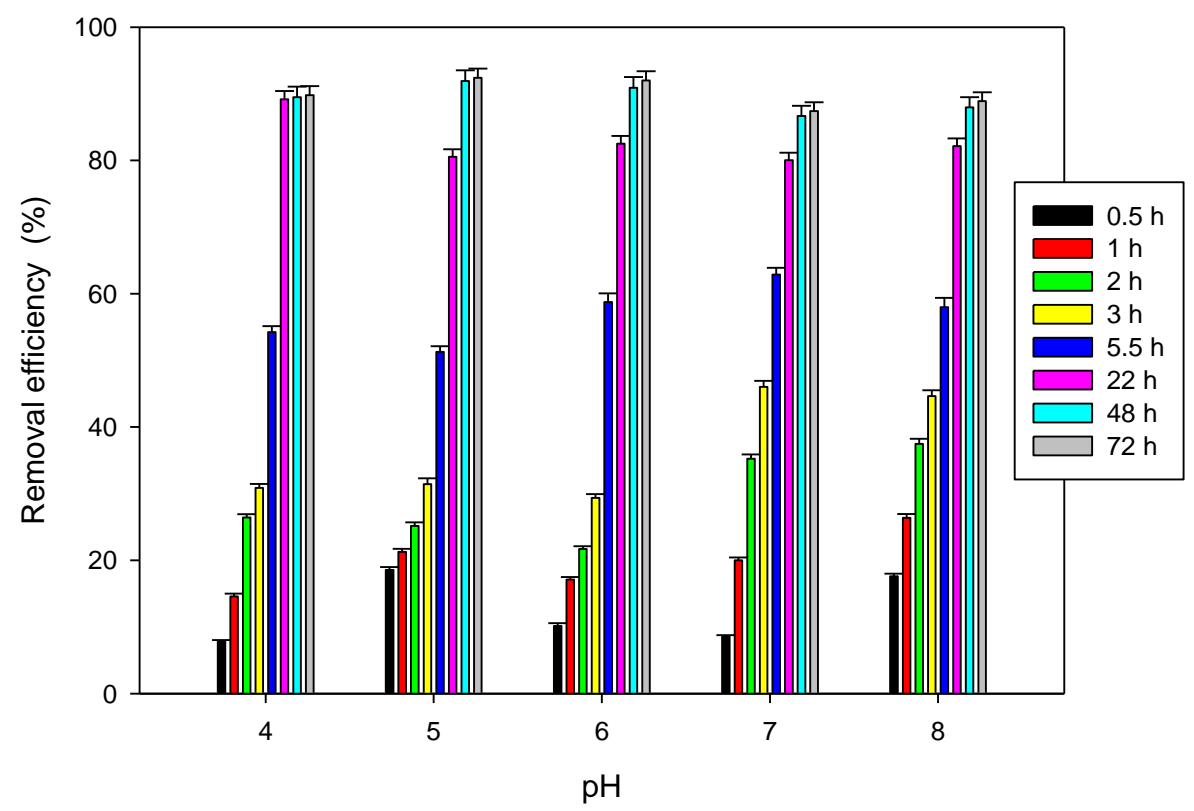

Figure 2. BPA removal efficiency of activated carbon AC-40 depending on $\mathrm{pH}$ at different contact times.

Considering the results obtained, from the removal efficiency point of view, a contact time of $48 \mathrm{~h}$ and a $\mathrm{pH}$ of 5 were selected for the rest of the experiments. There were not important differences in the $\mathrm{pH}$ range of 4 and 8 . An adjustment by addition of acidic/basic chemicals could represent an important part of the cost of the wastewater treatment process and for that reason, an economic evaluation could indicate other $\mathrm{pH}$ values as a better option.

\subsection{Influence of Adsorbent Dosage}

Figure 3 shows the results of tests performed to determine the minimum dose of activated carbon necessary to achieve maximum removal of BPA.

As the dosage of activated carbon increased, the BPA removal efficiency from solutions increased for all the contact times. However, differences between $0.5,0.75$ and $1 \mathrm{~g} / \mathrm{L}$ were very slight for long contacts times. For example, BPA removals (\%) of 92\%, 93\% and 90\% were achieved with adsorbent dosages of $0.5,0.75$ and $1 \mathrm{~g} / \mathrm{L}$, respectively, for a contact time of $48 \mathrm{~h}$. However, great differences were observed at very short times. For example, very high adsorption attained at $5.5 \mathrm{~h}$ when using $1 \mathrm{~g}$ of adsorbent per L. With regard to the amount of BPA adsorbed by gram of activated carbon, in general, it was higher for a dose of $0.5 \mathrm{~g} / \mathrm{L}$. Above this adsorbent dose, a decrease in the uptake of the BPA was observed. In conclusion, if time was not considered, the use of an adsorbent dose of $0.5 \mathrm{~g} / \mathrm{L}$ was recommended since at $22 \mathrm{~h}$ of operating time, very good BPA removals were achieved.

These results agreed with those obtained by numerous authors. Thus, Bautista-Toledo et al. [37] found an increase in the retention of BPA when $0.05 \mathrm{~g}$ of activated carbon was used for a period of $24 \mathrm{~h}$ in a BPA solution of $175 \mathrm{mg} / \mathrm{L}$. Liu et al. [11] reported an increase in retention of BPA with two carbons activated with nitric acid that were selectively modified. They obtained maximum adsorption of BPA (432 mg/g) when changing the amount of activated carbon used. Tsai et al. [55] detected an increase in retention of BPA when the dose of adsorbent increased. This occurred because the number of adsorption sites increased in parallel with the increase in the dose of the adsorbent, when the 
concentration of BPA was small $(<20 \mathrm{mg} / \mathrm{L})$. If the concentration was too high, the adsorbent would reach saturation quickly. As a result, it would stop contaminant retention.

According to the results, a concentration of $0.5 \mathrm{~g} / \mathrm{L}$ of activated carbon was selected, since at this concentration the minimum amount of adsorbent is used with good adsorption removal percentages (if enough contact time is maintained).

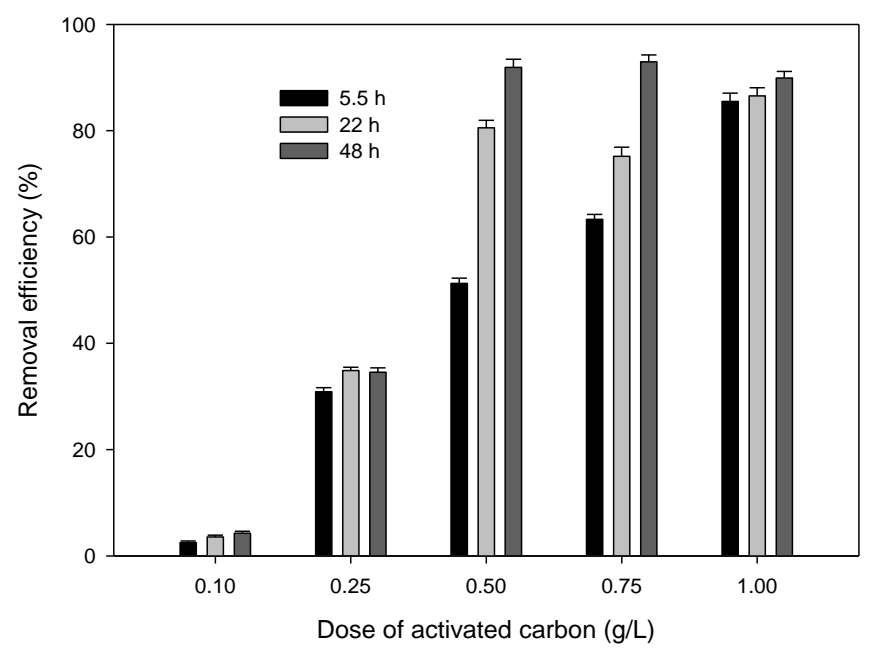

(a)

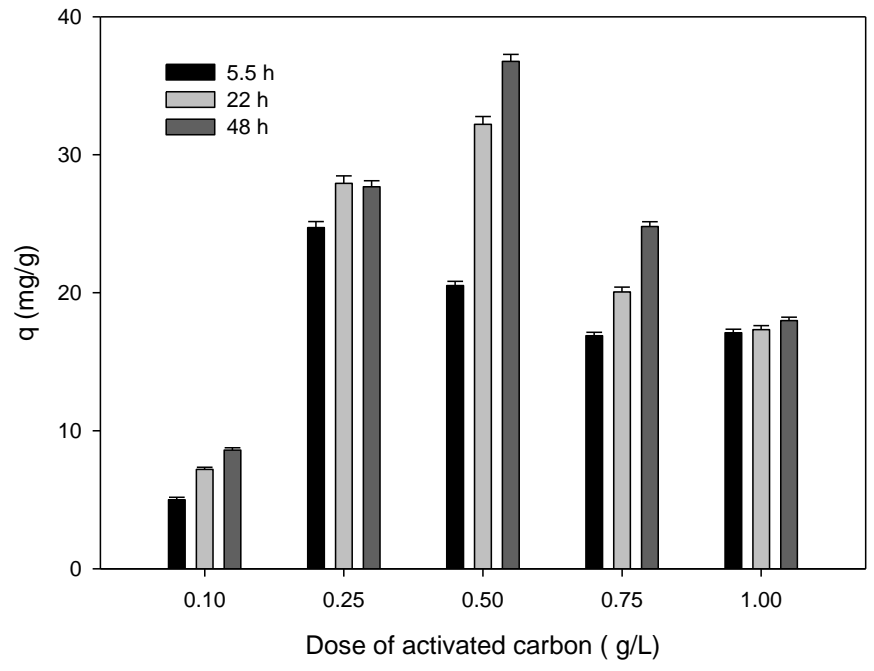

(b)

Figure 3. (a) BPA removal efficiency and (b) amount of BPA adsorbed by gram of activated carbon depending on adsorbent dosage at different contact times.

\subsection{Influence of the Initial Concentration of BPA}

Figure 4 shows the results of the influence of the initial concentration of BPA on its removal from the aqueous solution by AC-40. 


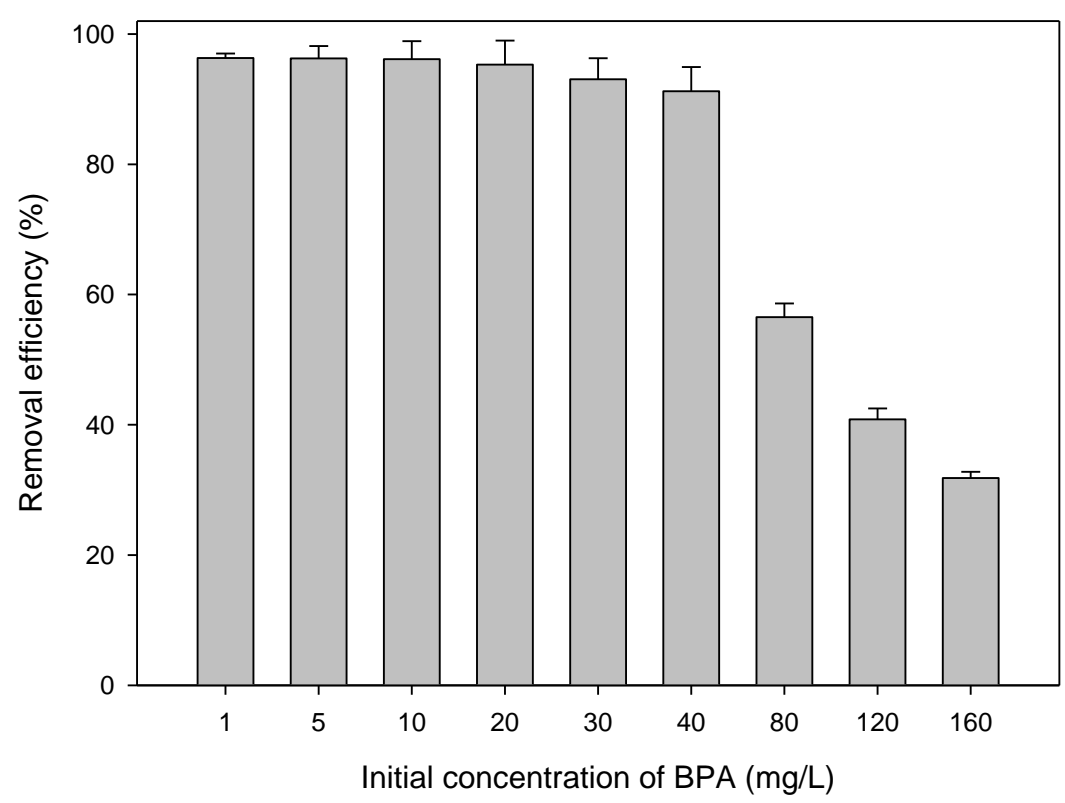

(a)

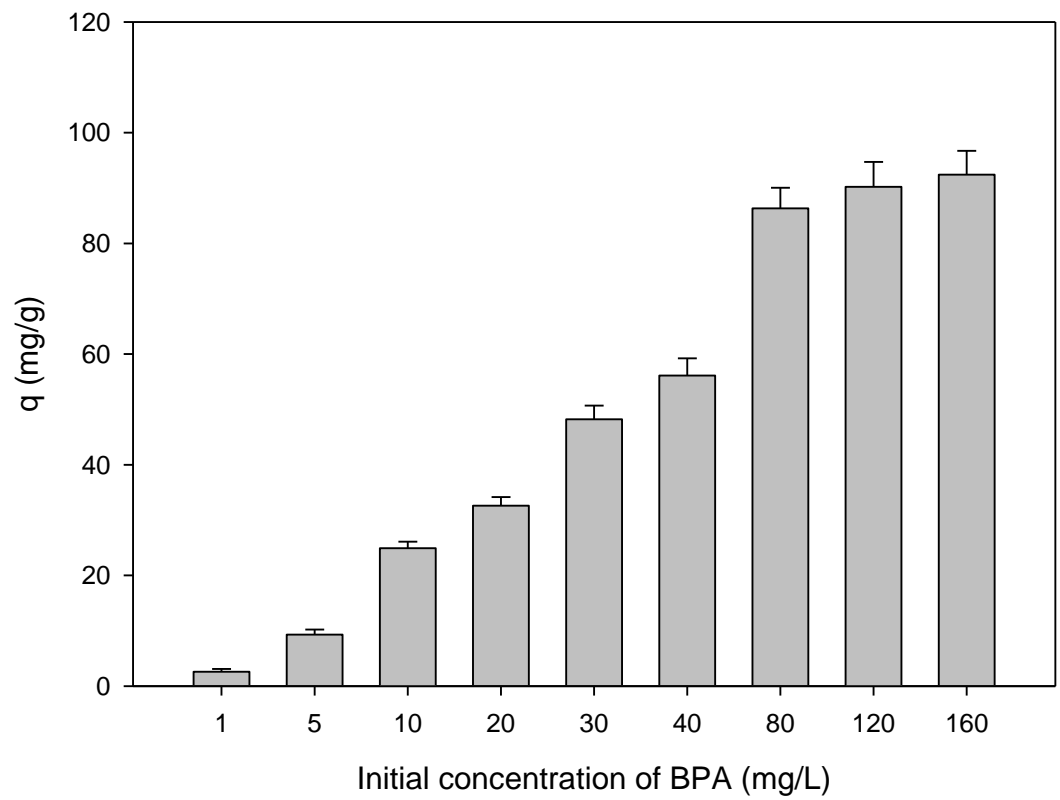

(b)

Figure 4. (a) BPA removal efficiency and (b) amount of BPA adsorbed by gram of activated carbon depending on initial concentration of BPA.

It should be noted that BPA concentration did not influence BPA removal (\%) for concentration values below $40 \mathrm{mg} / \mathrm{L}$ because the active sites on the adsorbent surface are not saturated. However, when the concentration was higher than $40 \mathrm{mg} / \mathrm{L}$, a significant decrease was observed in the adsorption percentage. In this sense, at concentrations of BPA below $80 \mathrm{mg} / \mathrm{L}$, the retention was higher because the pores of the carbon surface were occupied almost entirely. However, when the concentration of BPA was too high, the carbon surface underwent a supersaturation of its pores. As a consequence, a fraction of BPA was not retained by the adsorbent. These results were in agreement with those obtained by numerous authors. Thus, Bautista-Toledo et al. [37] obtained the same results in several studies with different concentrations of BPA and activated carbon. With regard to the amount of BPA removed expressed in $\mathrm{mg} / \mathrm{g}$ of adsorbent (Figure $4 \mathrm{~b}$ ), it increased from 2.6 to $92.4 \mathrm{mg} / \mathrm{g}$ with an increase in the 
initial concentration from 1 to $160 \mathrm{mg} / \mathrm{L}$. The main reason for this important increase is the increase in the mass transfer driving force [56].

Based on the results obtained, an initial concentration of $20 \mathrm{mg} / \mathrm{L}$ was selected as the initial concentration of BPA for the rest of the experiments.

\subsection{Kinetic Study}

A kinetics study in adsorption allows the determination of the BPA removal rate from the aqueous medium. This study provides a basis for understanding the mechanism that controls the process and it is essential to select the optimum operating conditions in the system designed for the effluent treatment with this type of pollutant $[57,58]$.

Experiments were performed with a total contact time of $48 \mathrm{~h}, \mathrm{pH}=5$, a BPA initial concentration of $20 \mathrm{mg} / \mathrm{L}$, an adsorbent concentration of $0.5 \mathrm{~g} / \mathrm{L}$ and a temperature of $298 \mathrm{~K}$. Figure 5 shows the values of $\mathrm{q}$ ( $\mathrm{mg}$ retained/g sorbent) versus time.

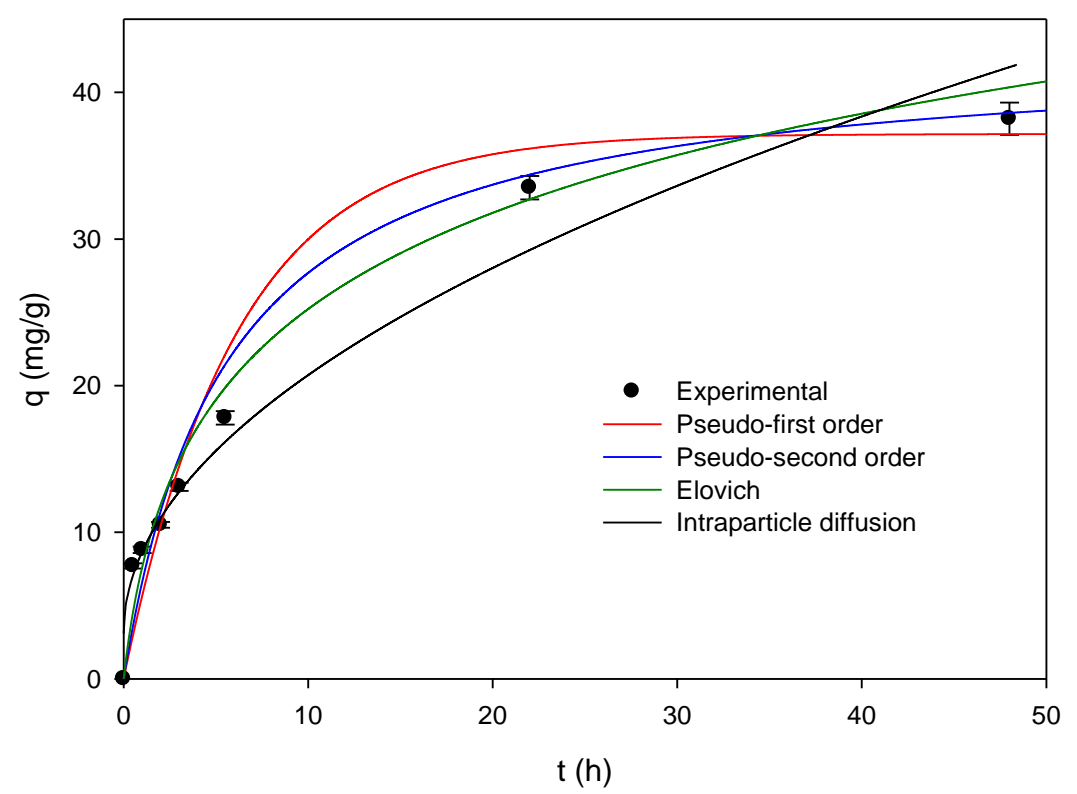

Figure 5. Variation in the adsorption capacity of BPA by activated carbon depending on the contact time and adjustment results of the four kinetic models.

These experimental results were fitted by a nonlinear regression to four kinetic models: pseudo-first-order, pseudo-second-order, Elovich and intraparticle diffusion models. Table 2 shows the representative equations of the models and their parameters. Likewise, Table 3 shows the results obtained when experimental data were fitted to the four selected kinetics models.

The pseudo-first- and pseudo-second-order models reproduced very well the experimental results. However, the intraparticle diffusion model showed a low $\mathrm{R}^{2}$ value. Specially, the good correlation coefficients $\left(R^{2}\right)$ of the pseudo-second-order model (it presented the highest $R^{2}$ value) and the similarity of the experimental and predicted adsorption capacity of this model indicated that the adsorption of BPA by activated carbon could be chemical adsorption, which is consistent with the results of Section 3.1. previously presented. In addition, the retention process was faster at first, but the equilibrium was not reached until $48 \mathrm{~h}$ of contact time. This indicates that, although adsorption happened quickly, the process subsequently proceeded more slowly until equilibrium was reached.

Other authors found similar results in their studies about BPA removal by activated carbons. Chang et al. [52] used an activated carbon obtained from rice straw agricultural waste. They found that the pseudo-second-order model fitted the experimental adsorption data better. Wang and Xiao [51] studied the adsorption of BPA by activated carbon reporting that the adsorption process followed the 
first-order kinetics. Soni and Padmaja [53] reported that the kinetic data of adsorption of BPA onto palm shell activated carbon could be fitted well by a pseudo-second-order kinetic model. Tang et al. [59] showed that the kinetics of BPA removal onto activated carbon-alginate beads with cetyltrimethyl ammonium bromide fitted good to the pseudo-first-order, pseudo-second-order and Elovich models.

Table 2. Equations and parameters representative of the four selected kinetic models.

\begin{tabular}{|c|c|c|}
\hline Model & Equation & Parameters \\
\hline Pseudo-first-order & $\mathrm{q}=\mathrm{q}_{\mathrm{e}}\left(1-\mathrm{e}^{-\mathrm{k}_{1} \cdot \mathrm{t}}\right)$ & $\begin{array}{l}\mathrm{q}_{\mathrm{e}} \text { adsorption capacity, } \mathrm{mg} / \mathrm{g} \\
\mathrm{k}_{1} \text { kinetic constant of the pseudo-first-order, } \mathrm{h}^{-1}\end{array}$ \\
\hline Pseudo-second-order & $\mathrm{q}=\frac{\mathrm{t}}{\frac{1}{\mathrm{k}_{2} \times \mathrm{qe}^{2}}+\frac{\mathrm{t}}{\mathrm{q}_{\mathrm{e}}}}$ & $\begin{array}{c}\mathrm{q}_{\mathrm{e}} \text { adsorption capacity, } \mathrm{mg} / \mathrm{g} \\
\mathrm{k}_{2} \text { kinetic constant of the pseudo-second-order, } \mathrm{g} / \mathrm{mg} \cdot \mathrm{h}\end{array}$ \\
\hline Elovich & $\mathrm{q}=\frac{1}{\mathrm{~b}} \ln (\mathrm{a} \times \mathrm{b})+\frac{1}{\mathrm{~b}} \ln (\mathrm{t})$ & $\begin{array}{l}\text { a velocity of initial adsorption, } \mathrm{mg} / \mathrm{g} \cdot \mathrm{h} \\
\mathrm{b} \text { area of the occupied surface, } \mathrm{g} / \mathrm{mg}\end{array}$ \\
\hline Intraparticle & $\mathrm{q}=\mathrm{k}_{\mathrm{p}} \times \mathrm{t}^{\frac{1}{2}}+\mathrm{C}$ & $\begin{array}{c}\mathrm{k}_{\mathrm{p}} \text { the intraparticle diffusion rate constant }\left(\mathrm{mg} /\left(\mathrm{g} \cdot \mathrm{min}^{1 / 2}\right)\right) \\
\mathrm{C} \text { constant of the intraparticle diffusion model }(\mathrm{mg} / \mathrm{g})\end{array}$ \\
\hline
\end{tabular}

Table 3. Adjustment results of the experimental data to the four selected kinetic models.

\begin{tabular}{cccc}
\hline Model & \multicolumn{3}{c}{ Parameters } \\
\hline Pseudo-first-order & $\mathrm{k}_{1}=0.164$ & $\mathrm{q}_{\mathrm{e}}=37.17$ & $\mathrm{r}^{2}=0.995$ \\
Pseudo-second-order & $\mathrm{k}_{2}=0.004$ & $\mathrm{q}_{\mathrm{e}}=43.06$ & $\mathrm{r}^{2}=1.000$ \\
Elovich & $\mathrm{a}=11.325$ & $\mathrm{~B}=0.099$ & $\mathrm{r}^{2}=0.992$ \\
Intraparticle diffusion & $\mathrm{k}_{\mathrm{p}}=5.577$ & $\mathrm{C}=3.082$ & $\mathrm{r}^{2}=0.964$ \\
\hline
\end{tabular}

\subsection{Equilibrium Study}

Figure 6 shows the retention capacity of BPA, qe (mg retained/g of sorbent when equilibrium is reached), versus the equilibrium concentration of BPA in the liquid phase, $C_{e}$.

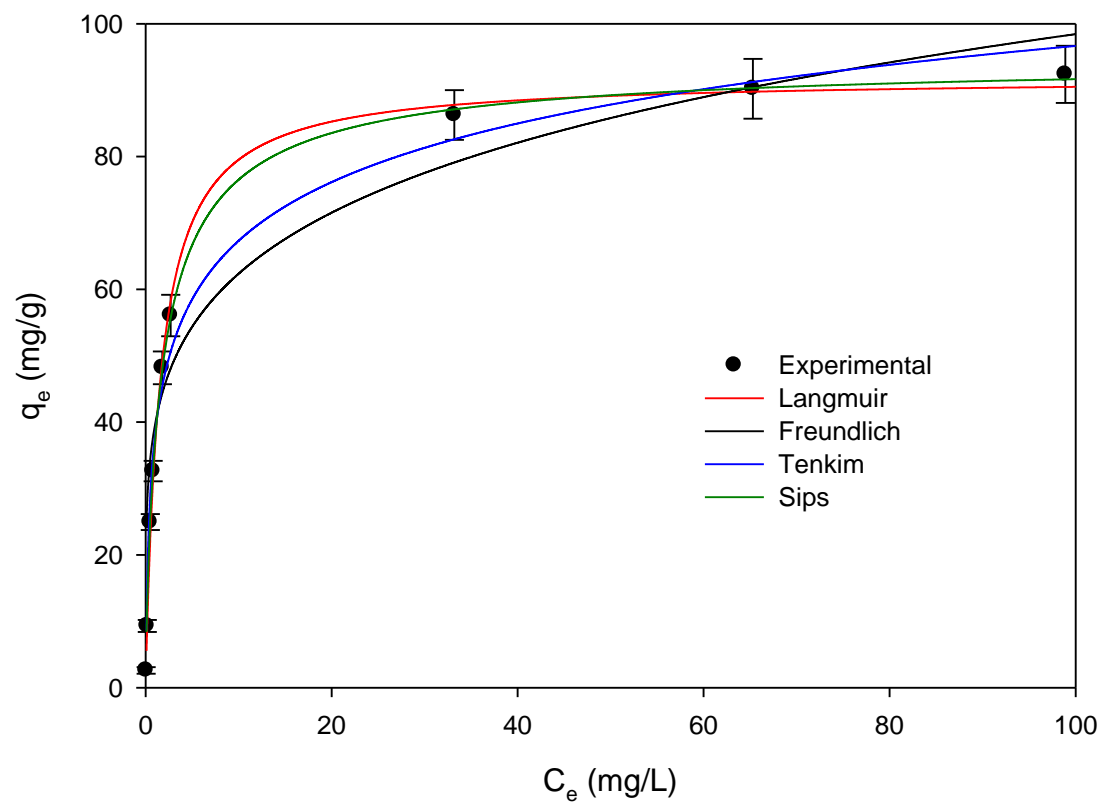

Figure 6. Equilibrium adsorption of BPA with activated carbon. Experimental results and adjustment to the selected models.

Different types of adsorption isotherms were found in the literature [51,60,61]. The isotherm obtained in this work was type I. The type I isotherm is monolayer adsorption easily explained using a Langmuir isotherm. Examples of type I adsorption isotherms are given by microporous solids such 
as activated carbon (material used in this study). It is also observed that the maximum adsorption capacity was close to $92 \mathrm{mg} / \mathrm{g}$, and it was reached when the initial concentration of BPA was $160 \mathrm{mg} / \mathrm{L}$.

In order to study the equilibrium of the process, these results have been adjusted to different models which are shown in Table 4. Further, Table 5 shows the fitting results and the parameters of the models obtained. Figure 7 represents the isotherm obtained with the models used.

The Langmuir and Sips models were the best in reproducing the experimental results, as the value of the parameter $n$ of the Sips isotherm was equal to the unit, which indicated that this model tended to be a Langmuir isotherm. This result indicates that adsorption is monolayer on the active sites of the adsorbent that has a homogeneous surface and molecules do not interact with each other. Likewise, the value of the maximum adsorption obtained with the Langmuir and Sips models was very close to the result obtained experimentally. These findings were similar to those obtained by other authors [52-54]. However, maximum capacity values of adsorption of AC-40 activated carbon were higher than those reported in the literature [62-65].

Finally, although adsorption processes performed in batch systems applied to the decontamination of wastewater are more frequent to determine the maximum adsorption capacity as the maximum amount of chemical adsorbed onto the adsorbent by mass of the adsorbent, in this work, the partition coefficients at the studied concentrations were also determined as the ratio of the concentration of BPA in solid phase (AC-40) to the concentration in liquid phase when the two concentrations are at equilibrium. Table 6 shows the partition coefficient as a function of the initial concentration of BPA. Data showed that the degree of partitioning varied with concentration. The linear partition coefficient was about 50-52 L/g (the amount adsorbed versus its solution concentration) at initial BPA concentrations lower or equal than $10 \mathrm{mg} / \mathrm{L}$. This can be observed in Figure 6 since the first experimental points were plotted in a linear trend. However, as the initial concentration of BPA increased, the linear partition coefficient decreased until approximately $1 \mathrm{~L} / \mathrm{g}$ at $160 \mathrm{mg} / \mathrm{L}$. It also can be observed in the change of the slope of the isotherm (Figure 6) as the BPA concentration was increased. In adsorption studies, when an L-type plot (isotherm) is obtained, the $\mathrm{q}_{\mathrm{m}}$ coefficient is a convenient and reliable parameter to be applied for adsorption capacities assessment better than the partition coefficient.

Table 4. Representative equations and parameters of the four selected models for the study of the equilibrium process.

\begin{tabular}{|c|c|c|}
\hline Model & Equation & Parameters \\
\hline Langmuir & $\mathrm{q}_{\mathrm{e}}=\frac{\mathrm{bq}}{1+\mathrm{b}} \frac{\mathrm{C}_{\mathrm{e}}}{\mathrm{C}_{\mathrm{e}}}$ & $\begin{array}{l}\mathrm{q}_{\mathrm{m}} \text { maximum adsorption capacity, } \mathrm{mg} / \mathrm{g} \\
\mathrm{b} \text { constant related to the affinity of the adsorbent for the adsorbate }\end{array}$ \\
\hline Freundlich & $\mathrm{q}_{\mathrm{e}}=\mathrm{K}_{\mathrm{F}} \times \mathrm{C}_{\mathrm{e}}^{\frac{1}{\mathrm{n}}}$ & $\begin{array}{l}\mathrm{K}_{\mathrm{F}} \text { equilibrium constant, }(\mathrm{mg} / \mathrm{g}) \cdot(\mathrm{L} / \mathrm{mg})^{1 / \mathrm{n}} \\
\text { n constant related to the affinity between the adsorbent and the adsorbate }\end{array}$ \\
\hline Sips & $\mathrm{q}_{\mathrm{e}}=\frac{\mathrm{q}_{\mathrm{m}} \mathrm{bC} \mathrm{e}_{\mathrm{e}}^{1 / \mathrm{n}}}{1+\mathrm{b} \mathrm{C}_{\mathrm{e}}^{1 / \mathrm{n}}}$ & $\begin{array}{l}\mathrm{q}_{\mathrm{m}} \text { maximum adsorption capacity, } \mathrm{mg} / \mathrm{g} \\
\mathrm{b} \text { constant related to the affinity of the adsorbent for the adsorbate } \\
\mathrm{n} \text { parameter characterizing the system's heterogeneity }\end{array}$ \\
\hline Temkin & $\begin{array}{c}\mathrm{q}_{\mathrm{e}}= \\
\frac{\mathrm{RT}}{\mathrm{b}} \ln \left(\mathrm{A}_{\mathrm{T}} \mathrm{C}_{\mathrm{e}}\right)\end{array}$ & $\begin{array}{l}\mathrm{A}_{\mathrm{T}} \text { constant of union of the equilibrium }(\mathrm{L} / \mathrm{g}) \text {, } \\
\text { b Temkin constant, } \\
\text { B constant related to the heat of adsorption }(\mathrm{J} / \mathrm{mol}) \text {, } \\
\mathrm{B}=\frac{\mathrm{RT}}{\mathrm{b}}\end{array}$ \\
\hline
\end{tabular}

Table 5. Adjustment results of the experimental data to the four selected isotherm models.

\begin{tabular}{cccc}
\hline Model & \multicolumn{3}{c}{ Parameters } \\
\hline Langmuir & $\mathrm{q}_{\mathrm{m}}=91.90$ & $\mathrm{~b}=0.64$ & $\mathrm{r}^{2}=0.996$ \\
Freundlich & $\mathrm{K}_{\mathrm{F}}=39.49$ & $\mathrm{n}=5.04$ & $\mathrm{r}^{2}=0.941$ \\
Sips & $\mathrm{q}_{\mathrm{m}}=95.06$ & $\mathrm{~b}=0.632 \quad \mathrm{n}=1.23$ & $\mathrm{r}^{2}=1.000$ \\
Temkin & $\mathrm{b}=194.47$ & $\mathrm{~A}_{\mathrm{T}}=19.65$ & $\mathrm{r}^{2}=0.981$ \\
\hline
\end{tabular}




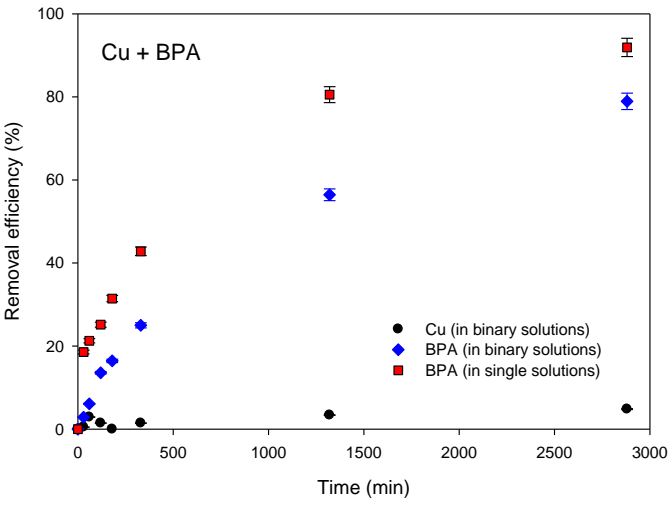

(a)

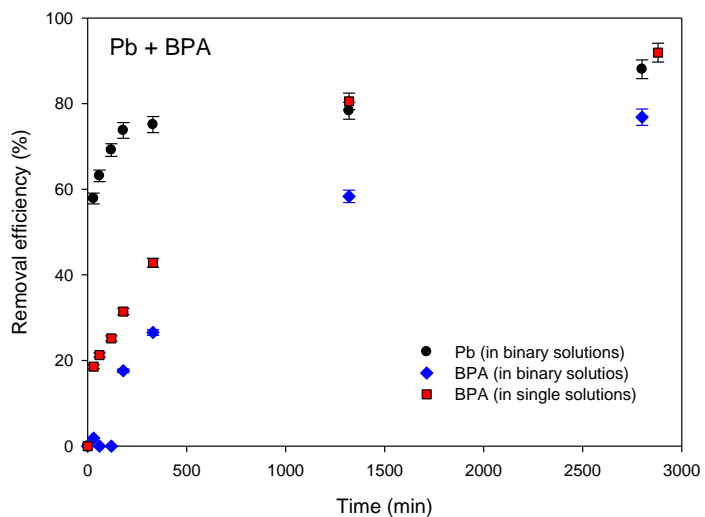

(c)

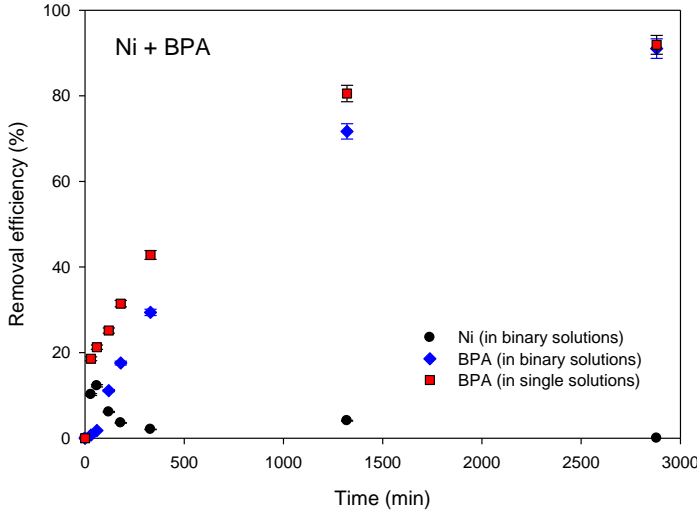

(b)

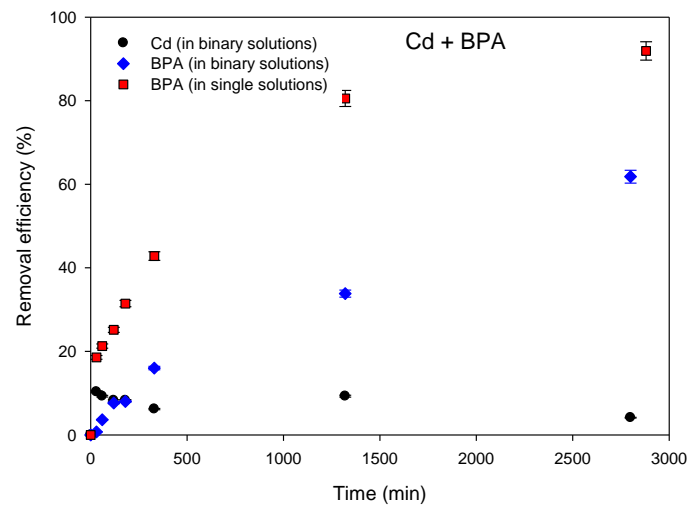

(d)

Figure 7. BPA removal (\%) in single solutions (red marker) and in binary solutions with (a) copper, (b) nickel, (c) lead and (d) cadmium (black marker for metal and blue one for BPA) using activated carbon AC-40 as the adsorbent.

Table 6. Partition coefficient in function of concentration.

\begin{tabular}{cc}
\hline Initial Concentration of BPA, $\mathbf{~ g / L}$ & Partition Coefficients, $\mathbf{L} / \mathbf{g}$ \\
\hline 1 & 52.00 \\
5 & 51.40 \\
10 & 49.80 \\
20 & 40.75 \\
30 & 26.78 \\
40 & 20.78 \\
80 & 2.60 \\
120 & 1.38 \\
160 & 0.93 \\
\hline
\end{tabular}

\subsection{Adsorption of BPA-Metals Cations Mixtures}

Different contaminants such as BPA and a wide variety of metal ions could be present in wastewater. The presence of these ions in solution can lead to competition between metals and the contaminant for the union with the adsorptive sites but also could enhance the BPA adsorption. For example, Han et al. [39] analyzed the influence of copper (II) and lead (II) ions on the adsorption of BPA onto lignin. These researchers found that the presence of the metal cations modified the surface of lignin, 
converting it on a less negatively charged surface. It was an advantage for the adsorption of anion species of BPA. Further, Liu et al. [38] studied the simultaneous adsorption of BPA and cadmium (II) ions on activated montmorillonite and found that the maximum adsorption capacity of BPA changed from 74.55 to $80.77 \mathrm{mg} / \mathrm{g}$ when cadmium was presented in the solution. Similarly, Bautista-Toledo et al. [37] reported that the presence of chromium (III) enhanced the adsorption of BPA on different activated carbons. The authors attributed the improvement in BPA adsorption to the in situ formation of complex compounds formed by $\mathrm{Cr}$ (III) and BPA (Cr (III)-BPA coordination compounds).

In this section, the interaction of some metal cations present in water with BPA was analyzed. The aim was to observe the possible interactions between the metal and the contaminant and/or metal and adsorbent, especially if they had synergistic properties. In all cases, the experiments of mixtures of metals and BPA have been compared with the initial experiment using only BPA. Cadmium, copper, lead and nickel were selected as the representatives of heavy metals because they are very common in wastewater. Figures 7 and 8 show the results.

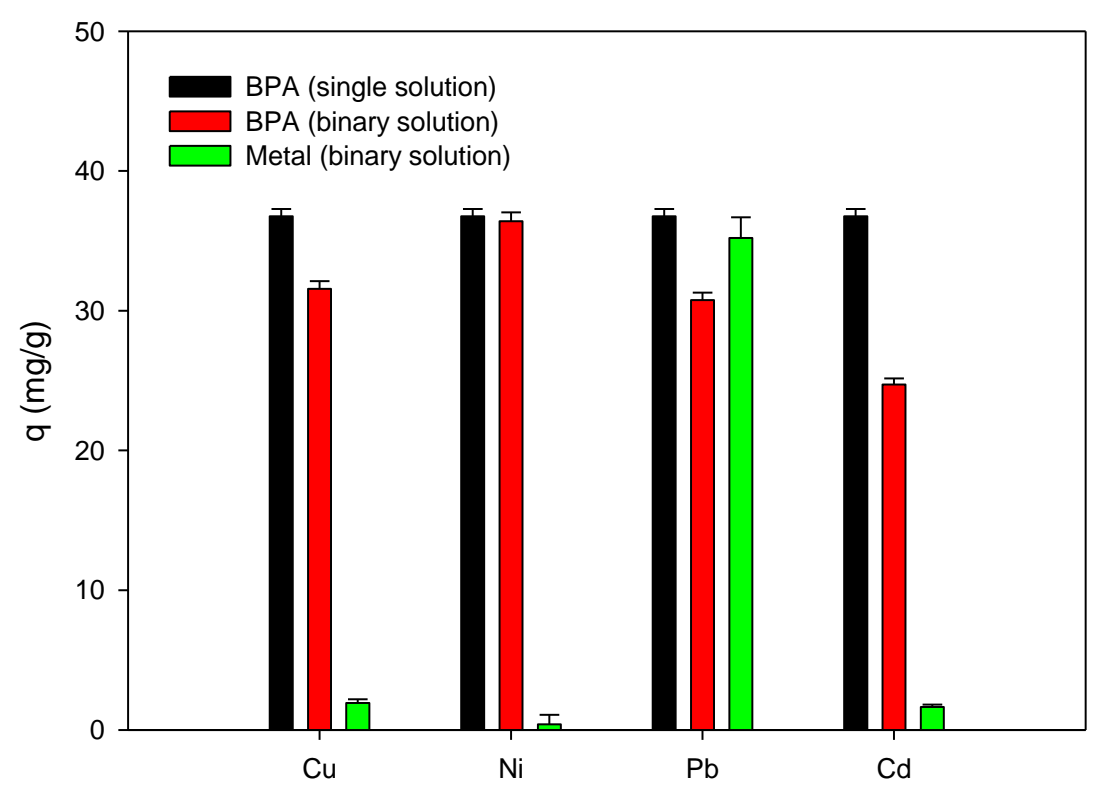

Figure 8. BPA adsorption capacity in single solutions (black color) and in binary solutions with different heavy metals (green marker for metal and red one for BPA) using activated carbon AC-40 as the adsorbent.

Contrary to the referenced studies of Han et al. [39], Lui et al. [38] and Bautista-Toledo et al. [37], the results showed that none of the metal cations improved the efficiency or adsorption capacity of BPA, suggesting a competition with BPA to occupy the porous surface of carbon and consequently decreasing its effectiveness. This is consistent with investigations carried out by Schiewer and Volesky [66], who systematically studied the effect of ionic strength on the adsorption of cations such as $\mathrm{Zn}^{2+}, \mathrm{Cd}^{2+}, \mathrm{Cu}^{2+}$ and $\mathrm{Na}^{+}$. They reported that an increase in ionic strength led to a decrease in the adsorption achieved due to the increase in the electrostatic charge. Niu and Volesky [67] studied the removal of anionic metal complexes $\left(\mathrm{Au}(\mathrm{CN})^{2-}, \mathrm{CrO}_{4}{ }^{2-}, \mathrm{SeO}_{4}{ }^{2-}\right.$ and $\left.\mathrm{VO}_{4}{ }^{3-}\right)$, concluding that an increase in ionic strength decreases the removal.

In the case of the mixture of Cd (II) and BPA, retention of BPA on activated carbon decreased. The difference in adsorption of BPA in the mixture solution (metal-BPA) and in the BPA solution was significant. BPA adsorption capacity changed from 36.8 (single solution) to $24.7 \mathrm{mg} / \mathrm{g}$ (binary solution). However, $\mathrm{Cd}$ was not greatly adsorbed (adsorption capacity of $1.6 \mathrm{mg} / \mathrm{g}$ ). This also occurred in mixtures of $\mathrm{Cu}$ (II) and BPA, although to a lesser extent. If the predominant binding force of BPA is electrostatic attraction, a decrease in the positively charged sites on the carbon surface could negatively influence the BPA adsorption. A change in the charge of the carbon surface and $\mathrm{pH}$ of the solution 
during the process due to the adsorption of metals could explain the decrease in the BPA adsorption. Earlier studies reported that the ionic strength of the solution notably influenced the adsorption of different species $[37,67,68]$. Further, Meng et al. [69] studied the adsorption of phenol and cadmium onto soil and found that the adsorption of mixed pollutants $\left(\mathrm{Cd}^{2+}\right.$ and phenol) showed an antagonistic effect on adsorption. Chemical adsorption was the main mechanism of adsorption of cadmium ions while physical adsorption was the primary mechanism for phenol adsorption (very influenced by the physic-chemical properties of the carbon surface). This indication was consistent with the $\mathrm{pH}$ evolution of the system (Table 7) and the point of zero charge reported in Table 1. The net charge of activated carbon decreases with the increase in $\mathrm{pH}$ values. Yang et al. [70] noted that the electrostatic surface charge was smaller with the $\mathrm{pH}$ of the adsorption system closer to the $\mathrm{pH}_{\mathrm{pzc}}$ of the activated carbon. In addition, BPA exists in its molecular form under $\mathrm{pH}<8$ but begins to deprotonate to a negatively charged form at around $\mathrm{pH} 8[13,51,70]$. Thus, when $\mathrm{pH}$ was increased above 7.5 , a repulsive electrostatic interaction may be established between the negatively charged surface of the activated carbon and bisphenolate anion. In the mixture of Ni (II) and BPA, the metal was not adsorbed and BPA removal in the mixture solution was very similar to the BPA removal in the single BPA solution. This means that the presence of Ni (II) did not affect the adsorption of BPA. Finally, in the case of the mixture of $\mathrm{Pb}$ (II) and BPA, the results suggested that both $\mathrm{Pb}$ (II) and BPA were notably adsorbed by activated carbon, probably because they formed a complex in situ with activated carbon, adsorbing and synergistically removing both contaminants present in the solution, or perhaps they distributed the available active sites of the adsorbent for $\mathrm{Pb}$ and $\mathrm{BPA}$ adsorption.

Table 7. $\mathrm{pH}$ evolution on simultaneous adsorption experiments.

\begin{tabular}{ccccc}
\hline Time, min & Cd (II) + BPA & Cu (II) + BPA & Ni (II) + BPA & Pb (II) + BPA \\
\hline 0 & 5 & 5 & 5 & 5 \\
30 & 6.9 & 6.3 & 6.2 & 6.4 \\
60 & 7.5 & 6.7 & 6.5 & 6.8 \\
120 & 7.8 & 6.8 & 6.6 & 7.1 \\
240 & 8.1 & 7.2 & 7.0 & 7.2 \\
480 & 8.0 & 7.5 & 7.0 & 7.3 \\
1440 & 8.0 & 7.4 & 7.3 & 7.3 \\
2880 & 7.9 & 7.6 & 7.5 & 7.5 \\
\hline
\end{tabular}

In conclusion, the metal ions may affect the sorption of BPA on AC-40 from different aspects: (1) the metal ions can reduce the BPA adsorption due to the decrease in sorption sites on the AC surface; (2) the metal ions can change the ionic strength of the solution and influence the adsorption of the different species; (3) the metal ions can promote the hydrophobic interaction, which may enhance the BPA adsorption on AC; and (4) the metal ions can promote the formation of complex compounds (metal-BPA coordination compounds) which increase the BPA adsorption.

\subsection{Cycles of BPA Adsorption/Desorption}

The reuse of AC-40 was investigated in three consecutive cycles of adsorption/desorption, without significant loss in the adsorption capacity. The adsorption capacity in the three consecutive adsorption-desorption cycles is reported in the Table 8. Figure 9 shows the desorption percentage of BPA. The removal efficiency was higher than $90 \%$ in all cases, indicating that the activated carbon has good reusability. Further, desorption of BPA from the AC- 40 was about $86.3 \%$ in the first desorption cycle and only decreased slightly after three adsorption-desorption cycles. These results indicated that the interaction of the BPA molecule to the binding sites on the adsorbent surface can be disrupted without any effect on the properties of the adsorbent. Similar results were found by other authors in their studies of the desorption of BPA by mixtures of methanol-acetic acid [71-73]. 
Table 8. Removal efficiency and adsorption capacity of BPA adsorption in three consecutive cycles.

\begin{tabular}{ccc}
\hline Cycle & \% Removal & $\mathbf{q}, \mathbf{m g} / \mathbf{g}$ \\
\hline 1 & 92.5 & 37.00 \\
2 & 91.4 & 36.56 \\
3 & 90.2 & 36.08 \\
\hline
\end{tabular}

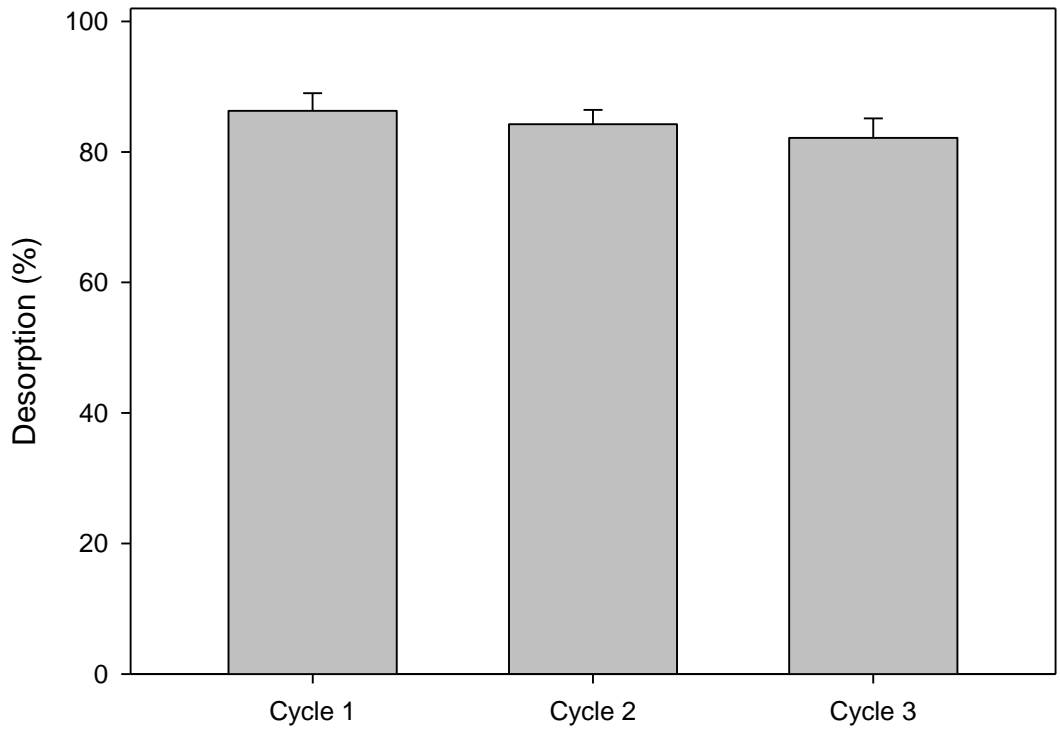

Figure 9. BPA desorption (\%) in each adsorption-desorption cycle.

\section{Conclusions}

The aim of this work was to investigate the application of a commercial activated carbon (AC-40) to remove BPA in single and simultaneous adsorption systems. The results showed that $\mathrm{pH}$ did not significantly affect the BPA adsorption at low $\mathrm{pH}$ values. However, when the acidity of the medium was increased, a slight improvement in the removal efficiencies was observed. Further, as the dose of activated carbon increased, the BPA removal efficiency increased at all contact times. Additionally, the concentration of BPA did not influence the adsorption, for the values of initial BPA concentration analyzed in this work (similar to those than can be found in some industrial wastewaters).

The isotherm obtained for BPA adsorption onto AC-40 was type I and the maximum adsorption capacity was close to $90 \mathrm{mg} / \mathrm{g}$. The Langmuir and Sips models were the best to reproduce the experimental results.

The experiments with mixtures of metals and BPA showed that none of the metal cations analyzed improved the efficiency of the adsorption process. In the case of the mixtures of $\mathrm{Pb}$ (II) and BPA, the results seemed to indicate that both $\mathrm{Pb}$ (II) and BPA can be efficiently removed from wastewater using AC-40.

Desorption tests showed good desorption efficiency (higher than $80 \%$ ) and also BPA adsorption capacities were very similar after three adsorption-desorption cycles, indicating that the activated carbon has good reusability. In conclusion, results of the work showed good adsorptive behavior of AC-40 for BPA removal in batch systems in single- and binary-solute adsorption. However, from a practical point of view and as a potential research line, complete experimental research on packed-bed columns including desorption studies should be carried out.

Author Contributions: Conceptualization, M.C.; formal analysis, M.A.M.-L. and C.E.; investigation, M.A.M.-L. and C.E.; methodology, M.A.M.-L., A.R. and M.C.; software, I.I.-R. and C.E.; supervision, M.A.M.-L.; validation, C.E.; resources, M.C.; writing-original draft, M.A.M.-L., A.R., I.I.-R., and C.E.; writing-review and editing, M.A.M.-L. and M.C. All authors have read and agreed to the published version of the manuscript.

Funding: This research received no external funding. 
Acknowledgments: Authors thank M.I. Bautista-Toledo for the activated carbon donation.

Conflicts of Interest: The authors declare no conflict of interest.

\section{References}

1. Gonsioroski, A.; Mourikes, V.E.; Flaws, J.A. Endocrine disruptors in water and their effects on the reproductive system. Int. J. Mol. Sci. 2020, 21, 1929. [CrossRef] [PubMed]

2. Rubin, B.S. Bisphenol A: An endocrine disruptor with widespread exposure and multiple effects. J. Steroid Biochem. Mol. Biol. 2011, 127, 27-34. [CrossRef] [PubMed]

3. Orimolade, B.O.; Adekola, F.A.; Adebayo, G.B. Adsorptive removal of bisphenol A using synthesized magnetite nanoparticles. Appl. Water Sci. 2018, 8, 46. [CrossRef]

4. ISH Markit. Bisphenol A. Chemical Economics Handbook; HIS Markit: London, UK, 2018.

5. Inoue, M.; Masuda, Y.; Okada, F.; Sakurai, A.; Takahashi, I.; Sakakibara, M. Degradation of bisphenol A using sonochemical reactions. Water Res. 2008, 42, 1379-1386. [CrossRef]

6. Ivanov, A.E.; Halthur, T.; Ljunggren, L. Flow permeable composites of lignin and poly(vinyl alcohol): Towards removal of bisphenol A and erythromycin from water. J. Environ. Chem. Eng. 2016, 4, 1432-1441. [CrossRef]

7. Santhi, V.A.; Sakai, N.; Ahmad, E.D.; Mustafa, A.M. Occurrence of bisphenol A in surface water, drinking water and plasma from Malaysia with exposure assessment from consumption of drinking water. Sci. Total Environ. 2012, 427, 332-338. [CrossRef]

8. Vandenberg, L.N.; Hauser, R.; Marcus, M.; Olea, N.; Welshons, W.V. Human exposure to bisphenol A (BPA). Reprod. Toxicol. 2007, 24, 139-177. [CrossRef]

9. Yamamoto, T.; Yasuhara, A.; Shiraishi, H.; Nakasugi, O. Bisphenol A in hazardous waste landfill leachates. Chemosphere 2001, 42, 415-418. [CrossRef]

10. Phouthavong-Murphy, J.C.; Merrill, A.K.; Zamule, S.; Giacherio, D.; Brown, B.; Roote, C.; Das, P. Phytoremediation potential of switchgrass (Panicum virgatum), two United States native varieties, to remove bisphenol-A (BPA) from aqueous media. Sci. Rep. 2020, 10, 835. [CrossRef]

11. Liu, G.; Ma, J.; Li, X.; Qin, Q. Adsorption of bisphenol A from aqueous solution onto activated carbons with different modification treatments. J. Hazard. Mater. 2009, 164, 1275-1280. [CrossRef]

12. Yeo, M.K.; Kang, M. Photodecomposition of bisphenol A on nanometer-sized $\mathrm{TiO}_{2}$ thin film and the associated biological toxicity to zebrafish (Danio rerio) during and after photocatalysis. Water Res. 2006, 40, 1906-1914. [CrossRef] [PubMed]

13. Wang, J.; Zhang, M. Adsorption Characteristics and mechanism of bisphenol A by magnetic biochar. Int. J. Environ. Res. Public Health 2020, 17, 1075. [CrossRef] [PubMed]

14. Ahmed, M.B.; Zhou, J.L.; Ngo, H.H.; Guo, W.S.; Thomaidis, N.S.; Xu, J. Progress in the biological and chemical treatment technologies for emerging contaminant removal from wastewater: A critical review. J. Hazard. Mater. 2017, 323, 274-298. [CrossRef] [PubMed]

15. Esplugas, S.; Bila, D.M.; Krause, L.G.T.; Dezotti, M. Ozonation and advanced oxidation technologies to remove endocrine disrupting chemicals (EDCs) and pharmaceuticals and personal care products (PPCPs) in water effluents. J. Hazard. Mater. 2007, 149, 631-642. [CrossRef] [PubMed]

16. Luo, H.; Cheng, Y.; Zeng, Y.; Luo, K.; He, D.; Pan, X. Rapid removal of organic micropollutants by heterogeneous peroxymonosulfate catalysis over a wide $\mathrm{pH}$ range: Performance, mechanism and economic analysis. Sep. Purif. Technol. 2020, 248, 117023. [CrossRef]

17. Lin, H.; Fang, Q.; Wang, W.; Li, G.; Guan, J.; Shen, Y.; Ye, J.; Liu, F. Prussian blue/PVDF catalytic membrane with exceptional and stable Fenton oxidation performance for organic pollutants removal. Appl. Catal. B Environ. 2020, 273, 119047. [CrossRef]

18. Rani, M.; Rachna; Shanker, U. Efficient photocatalytic degradation of Bisphenol A by metal ferrites nanoparticles under sunlight. Environ. Technol. Innov. 2020, 19, 100792. [CrossRef]

19. Nakanishi, A.; Tamai, M.; Kawasaki, N.; Nakamura, T.; Tanada, S. Adsorption characteristics of bisphenol A onto carbonaceous materials produced from wood chips as organic waste. J. Colloid Interface Sci. 2002, 252, 393-396. [CrossRef]

20. Marsh, H.; Heintz, E.A.; Rodriguez-Reinoso, F. Introduction to Carbon Technologies; University of Alicante: Alicante, Spain, 1997.

21. Bansal, R.C.; Donnet, J.-B.; Stoeckli, F. Active Carbon; Marcel Dekker: New York, NY, USA, 1988. 
22. Derbyshire, F.; Jagtoyen, M.; Andrews, R.; Rao, A.; Martin-Gullon, I.; Grulke, E. Carbon materials in environmental applications. Chem. Phys. Carbon 2001, 27, 1-66.

23. Musmarra, D.; Karatza, D.; Lancia, A.; Prisciandaro, M.; Mazziotti di Celso, G. Adsorption of elemental mercury vapors from synthetic exhaust combustion gas onto HGR carbon. J. Air Waste Manag. Assoc. 2016, 66, 698-706. [CrossRef]

24. Rivera-Utrilla, J.; Sánchez-Polo, M.; Gómez-Serrano, V. Activated carbon modifications to enhance its water treatment applications. An overview. J. Hazard. Mater. 2011, 187, 1-23. [CrossRef] [PubMed]

25. Dias, J.M.; Alvim-Ferraz, M.C.M.; Almeida, M.F.; Rivera-Utrilla, J.; Sánchez-Polo, M. Waste materials for activated carbon preparation and its use in aqueous-phase treatment: A review. J. Environ. Manag. 2007, 85, 833-846. [CrossRef]

26. Moreno-Castillo, C.; Rivera-Utrilla, J. Carbon materials as adsorbents for the removal of pollutants from the aqueous phase. Mater. Res. Bull. 2001, 26, 890-894. [CrossRef]

27. Radovic, L.R.; Moreno-Castilla, C.; Rivera-Utrilla, J. Chemistry and Physics of Carbon; Radovic, L.R., Ed.; Marcel Dekker: New York, NY, USA, 2000; Volume 27, p. 227.

28. Chen, J.; Zhang, L.; Yang, G.; Wang, Q.; Li, R.; Lucia, L.A. Preparation and characterization of activated carbon from hydrochar by phosphoric acid activation and its adsorption performance in prehydrolysis liquor. BioResources 2017, 12, 5928-5941. [CrossRef]

29. Jagtoyen, M.; Thwaites, M.; Stencel, J.; McEnaney, B.; Derbyshire, F. Adsorbent carbon synthesis from coals by phosphoric acid activation. Carbon 1992, 30, 1089-1096. [CrossRef]

30. Bhatnagar, A.; Anastopoulos, I. Adsorptive removal of bisphenol A (BPA) from aqueous solution: A review. Chemosphere 2017, 168, 885-902. [CrossRef] [PubMed]

31. Juhola, R.; Runtti, H.; Kangas, T.; Hu, T.; Romar, H.; Tuomikoski, S. Bisphenol A removal from water by biomass-based carbon: Isotherms, kinetics and thermodynamics studies. Environ. Technol. 2020, 41, 971-980. [CrossRef]

32. Lu, J.; Zhang, C.; Wu, J.; Luo, Y. Adsorptive removal of bisphenol A using N-doped biochar made of Ulva prolifera. Water Air Soil Pollut. 2017, 228, 327. [CrossRef]

33. Pan, B.; Lin, D.; Mashayekhi, H.; Xing, B. Adsorption and Hysteresis of Bisphenol A and 17-Ethinyl Estradiol on Carbon Nanomaterials. Environ. Sci. Technol. 2008, 42, 5480-5485. [CrossRef]

34. Redding, A.M.; Cannon, F.S.; Snyder, S.A.; Vanderford, B.J. A QSAR-like analysis of the adsorption of endocrine disrupting compounds, pharmaceuticals, and personal care products on modified activated carbons. Water Res. 2009, 43, 3849-3861. [CrossRef]

35. Solak, S.; Vakondios, N.; Tzatzimaki, I.; Diamadopoulos, E.; Arda, M.; Kabay, N.; Yüksel, M. A comparative study of removal of endocrine disrupting compounds (EDCs) from treated wastewater using highly crosslinked polymeric adsorbents and activated carbon. J. Chem. Technol. Biotechnol. 2014, 89, 819-824. [CrossRef]

36. Wu, Z.; Wei, X.; Xue, Y.; He, X.; Yang, X. Removal effect of atrazine in co-solution with bisphenol A or humic acid by different activated carbons. Materials 2018, 11, 2558. [CrossRef] [PubMed]

37. Bautista-Toledo, M.I.; Rivera-Utrilla, J.; Ocampo-Pérez, R.; Carrasco-Marín, F.; Sánchez-Polo, M. Cooperative adsorption of bisphenol-A and chromium(III) ions from water on activated carbons prepared from olive-mill waste. Chem. Eng. J. 2014, 73, 338-350. [CrossRef]

38. Liu, C.; Wu, P.; Zhu, Y.; Tran, L. Simultaneous adsorption of $\mathrm{Cd}^{2+}$ and BPA on amphoteric surfactant activated montmorillonite. Chemosphere 2016, 144, 1026-1032. [CrossRef]

39. Han, W.; Luo, L.; Zhang, S. Adsorption of bisphenol A on lignin: Effects of solution chemistry. Int. J. Environ. Sci. Technol. 2012, 9, 543-548. [CrossRef]

40. Hanladakis, J.N.; Velis, C.A.; Weber, R.; Iacovidou, E.; Purnell, P. An overview of chemical additives present in plastics: Migration, release, fate and environmental impact during their use, disposal and recycling. J. Hazard. Mater. 2018, 344, 179-199. [CrossRef] [PubMed]

41. Kyzas, G.Z.; Siafaka, P.I.; Pavlidou, E.G.; Chrissafis, K.J.; Bikiaris, D.N. Synthesis and adsorption application of succinyl-grafted chitosan for the simultaneous removal of zinc and cationic dye from binary hazardous mixtures. Chem. Eng. J. 2015, 259, 438-448. [CrossRef]

42. Stawinski, W.; Wegrzyn, A.; Freitas, O.; Chmielarz, L.; Mordarski, G.; Figueiredo, S. Simultaneous removal of dyes and metal cations using an acid, acid-base and base modified vermiculite as a sustainable and recyclable adsorbent. Sci. Total Environ. 2017, 576, 398-408. [CrossRef] [PubMed] 
43. Morosanu, I.; Teodosiu, C.; Fighir, D.; Paduraru, C. Simultaneous Biosorption of Micropollutants from Aqueous Effluents by Rapeseed Waste. Process Saf. Environ. Prot. 2019, 132, 231-239. [CrossRef]

44. Méndez-Díaz, J.D.; Abdel Daiem, M.M.; Rivera-Utrilla, J.; Sánchez-Polo, M.; Bautista-Toledo, I. Adsorption/bioadsorption of phthalic acid, an organic micropollutant present in landfill leachates, on activated carbons. J. Colloid Interface Sci. 2012, 369, 358-365. [CrossRef]

45. Abdel Daiem, M.M.; Rivera-Utrilla, J.; Sánchez-Polo, M.; Ocampo-Pérez, R. Single, competitive and dynamic adsorption on activated carbon of compounds used as plasticizers and herbicides. Sci. Total Environ. 2015, 537, 335-342. [CrossRef] [PubMed]

46. Velo-Gala, I.; López-Peñalver, J.J.; Sánchez-Polo, M.; Rivera-Utrilla, J. Role of activated carbon on micropollutants degradation by ionizing radiation. Carbon 2014, 67, 288-299. [CrossRef]

47. Bernal, V.; Erto, A.; Giraldo, L.; Moreno-Pijarán, J.C. Effect of solution pH on the adsorption of paracetamol on chemically modified activated carbons. Molecules 2017, 22, 1032. [CrossRef] [PubMed]

48. Pereira, R.C.; Anizelli, P.R.; Di Mauro, E.; Valezi, D.F.; da Costa, A.C.S.; Zaia, C.T.B.V.; Zaia, D.A.M. The effect of $\mathrm{pH}$ and ionic strength on the adsorption of glyphosate onto ferrihydrite. Geochem. Trans. 2019, $20,3$. [CrossRef] [PubMed]

49. Bautista-Toledo, M.I.; Ferro-García, M.A.; Rivera-Utrilla, J.; Moreno-Castilla, C.; Vegas, F.J. Bisphenol A removal from water by activated carbon. Effects of carbon characteristics and solution chemistry. Environ. Sci. Tecnhol. 2005, 39, 6246-6250. [CrossRef]

50. Tursi, A.; Chatzisymeon, E.; Chidichimo, F.; Beneduci, A.; Chidichimo, G. Removal of endocrine disrupting chemicals from water: Adsorption of bisphenol-A by biobased hydrophobic functionalized cellulose. Int. J. Environ. Res. Public Health 2018, 15, 2419. [CrossRef]

51. Wang, X.; Xiao, Y. Removal of the endocrine disrupting chemical Bisphenol A from water by activated carbon. Adv. Mater. Res. 2013, 671, 2726-2731. [CrossRef]

52. Chang, K.L.; Hsieh, J.F.; Ou, B.M.; Chang, M.H.; Hseih, W.Y.; Lin, J.F.; Huang, P.J.; Wong, K.F.; Chen, S.T. Adsorption studies on the removal of an endocrine-disrupting compound (Bisphenol A) using activated carbon from rice straw agricultural waste. Sep. Sci. Technol. 2012, 47, 1514-1521. [CrossRef]

53. Soni, H.; Padmaja, P. Palm shell based activated carbon for removal of bisphenol A: An equilibrium, kinetic and thermodynamic study. J. Hazard. Mater. 2014, 21, 275-284. [CrossRef]

54. Bohdziewicz, J.; Liszczyk, G. Evaluation of effectiveness of bisphenol a removal on domestic and foreign activated carbons. Ecol. Chem. Eng. Soc. 2013, 20, 371-379. [CrossRef]

55. Tsai, W.-T.; Lai, C.-W.; Su, T.-Y. Adsorption of bisphenol-A from aqueous solution onto minerals and carbon adsorbents. J. Hazard. Mater. 2006, 134, 169-175. [CrossRef] [PubMed]

56. Yu, J.; Shen, H.; Liu, B. Adsorption Properties of polyethersulfone-modified attapulgite hybrid microspheres for bisphenol A and sulfamethoxazole. Int. J. Environ. Res. Public Health 2020, 17, 473. [CrossRef]

57. Ho, Y.S.; Mckay, G. A comparison of chemisorption kinetic models applied to pollutant removal on various sorbents. Process Saf. Environ. Prot. 1998, 76, 332-340. [CrossRef]

58. King, P.; Srinivas, P.; Prasanna Kumar, Y.; Prasad, V.S.R.K. Sorption of copper(II) ion from aqueous solution by Tectona grandis l.f. (teak leaves powder). J. Hazard. Mater. 2006, 136, 560-566. [CrossRef] [PubMed]

59. Tang, Z.; Peng, S.; Hu, S.; Hong, S. Enhanced removal of bisphenol-AF by activated carbon-alginate beads with cetyltrimethyl ammonium bromide. J. Colloid Interface Sci. 2017, 495, 191-199. [CrossRef]

60. Rouquerol, F.; Rouquerol, J.; Sing, K.S.W.; Llewellyn, P.; Maurin, G. Adsorption by Powders and Porous Solids. Principles, Methodology and Applications, 2nd ed.; Elsevier: New York, NY, USA, 2012. [CrossRef]

61. Brunauer, S.; Deming, L.S.; Deming, W.E.; Teller, E. On a theory of the Van der Waals adsorption of gases. J. Am. Chem. Soc. 1940, 62, 1723-1732. [CrossRef]

62. Asada, T.; Oikawa, K.; Kawata, K.; Ishihara, S.; Iyobe, T.; Yamada, A. Study of removal effect of bisphenol A and $\beta$-estradiol by porous carbon. J. Health Sci. 2004, 50, 588-593. [CrossRef]

63. Kuo, C.-Y. Comparison with as-grown and microwave modified carbon nanotubes to removal aqueous bisphenol A. Desalination 2009, 249, 976-982. [CrossRef]

64. Li, S.; Gong, Y.; Yang, Y.; He, C.; Hu, L.; Zhu, L.; Sun, L.; Shu, D. Recyclable $\mathrm{CNTs} / \mathrm{Fe}_{3} \mathrm{O}_{4}$ magnetic nanocomposites as adsorbents to remove bisphenol A from water and their regeneration. Chem. Eng. J. 2015, 260, 231-239. [CrossRef]

65. Xu, J.; Zhu, Y.F. Elimination of bisphenol A from water via graphene oxide adsorption. Acta Phys. Chim. Sinica 2013, 29, 829-836. 
66. Schiewer, S.; Volesky, B. Modeling multi-metal ion exchange in biosorption. Environ. Sci. Technol. 1996, 30, 2921-2927. [CrossRef]

67. Niu, H.; Volesky, B. Biosorption mechanism for anionic metal species with waste crab shells. Eur. J. Miner. Proc. Environ. Prot. 2003, 3, 75-87.

68. López-Ramón, V.; Moreno-Castilla, C.; Rivera-Utrilla, J.; Radovic, L.R. Ionic strength effects in aqueous phase adsorption of metals ion son activated carbons. Carbon 2003, 41, 2020. [CrossRef]

69. Meng, Z.-F.; Zhang, Y.-P.; Zhang, Z.-Q. Simultaneous adsorption of phenol and cadmium on amphoteric modified soil. J. Hazard. Mater. 2008, 159, 492-498. [CrossRef] [PubMed]

70. Yan, L.; Huang, X.; Shi, H.; Zhang, G. Adsorption characteristics of bisfenol A on tailored activated carbon in aqueous solutions. Water Sci. Technol. 2016, 74, 1744-1751. [CrossRef] [PubMed]

71. Guo, W.; Hu, W.; Pan, J.; Zhou, H.; Guan, W.; Wang, X.; Dai, J.; Xu, L. Selective adsorption and separation of BPA from aqueous solution using novel molecularly imprinted polymers based on kaolinite/ $\mathrm{Fe}_{3} \mathrm{O}_{4}$ composites. Chem. Eng. J. 2011, 171, 603-611. [CrossRef]

72. Bayramoglu, G.; Arica, M.Y.; Liman, G.; Celikbicak, O.; Salih, B. Removal of bisphenol A from aqueous medium using molecularly surface imprinted microbeads. Chemosphere 2016, 150, 275-284. [CrossRef]

73. Yu, C.; Shan, J.; Chen, Y.; Shao, J.; Zhang, F. Preparation and adsorption properties of rosin-based bisphenol A molecularly imprinted microspheres. Mater. Today Commun. 2020, 24, 101076. [CrossRef]

(C) 2020 by the authors. Licensee MDPI, Basel, Switzerland. This article is an open access article distributed under the terms and conditions of the Creative Commons Attribution (CC BY) license (http://creativecommons.org/licenses/by/4.0/). 